Article

\title{
Novel Organochlorinated Xerogels: From Microporous Materials to Ordered Domains
}

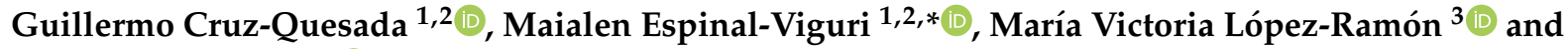 \\ Julián J. Garrido 1,2,*(D) \\ 1 Departamento de Ciencias, Edif. Los Acebos, Campus Arrosadía, Public University of Navarre, \\ 31006 Pamplona, Spain; guillermo.cruz@unavarra.es \\ 2 Institute for Advanced Materials and Mathematics, Edif. Jerónimo de Ayanz, Campus Arrosadía, Public \\ University of Navarre, 31006 Pamplona, Spain \\ 3 Departamento de Química Inorgánica y Orgánica; Facultad de Ciencias Experimentales, University of Jaén, \\ 23071 Jaen, Spain; mvlro@ujaen.es \\ * Correspondence: maialen.espinal@unavarra.es (M.E.-V.); j.garrido@unavarra.es (J.J.G.); \\ Tel.: +34-948-169604 (M.E.-V.); +34-948-168082 (J.J.G.)
}

check for updates

Citation: Cruz-Quesada, G.; Espinal-Viguri, M.; López-Ramón, M.V.; Garrido, J.J. Novel

Organochlorinated Xerogels: From Microporous Materials to Ordered Domains. Polymers 2021, 13, 1415. https: / / doi.org/10.3390/ polym13091415

Academic Editors: Jerzy J. Chruściel and Ignazio Blanco

Received: 9 April 2021

Accepted: 25 April 2021

Published: 27 April 2021

Publisher's Note: MDPI stays neutral with regard to jurisdictional claims in published maps and institutional affiliations.

Copyright: (c) 2021 by the authors. Licensee MDPI, Basel, Switzerland. This article is an open access article distributed under the terms and conditions of the Creative Commons Attribution (CC BY) license (https:/ / creativecommons.org/licenses/by/ $4.0 /)$.

\begin{abstract}
Hybrid silica xerogels combine the properties of organic and inorganic components in the same material, making them highly promising and versatile candidates for multiple applications. They can be tailored for specific purposes through chemical modifications, and the consequent changes in their structures warrant in-depth investigation. We describe the synthesis of three new series of organochlorinated xerogels prepared by co-condensation of tetraethyl orthosilicate (TEOS) and chloroalkyltriethoxysilane (CIRTEOS; $\mathrm{R}$ = methyl [M], ethyl [E], or propyl [P]) at different molar ratios. The influence of the precursors on the morphological and textural properties of the xerogels was studied using ${ }^{29}$ Si NMR (Nuclear Magnetic Resonance), FTIR (Fourier-Transform Infrared Spectroscopy), $\mathrm{N}_{2}$, and $\mathrm{CO}_{2}$ adsorption, XRD (X-ray Diffraction), and FE-SEM (Field-Emission Scanning Electron Microscopy). The structure and morphology of these materials are closely related to the nature and amount of the precursor, and their microporosity increases proportionally to the molar percentage of CIRTEOS. In addition, the influence of the chlorine atom was investigated through comparison with their non-chlorinated analogues (RTEOS, R = M, E, or P) prepared in previous studies. The results showed that a smaller amount of precursor was needed to detect ordered domains (ladders and $\mathrm{T}_{8}$ cages) in the local structure. The possibility of coupling selforganization with tailored porosity opens the way to novel applications for this type of organically modified silicates.
\end{abstract}

Keywords: xerogels; hybrid materials; TEOS; chloroalkyltriethoxysilane; inductive effect; textural properties; ORMOSILs

\section{Introduction}

The demand for materials with specific physicochemical properties has markedly increased over the past decade. Research has focused on the design of hybrid solids in which organic and inorganic species coexist on a nanometric scale, with the aim of generating synergistic effects and tailored materials. Organically modified silicates (ORMOSILs) are hybrid silicon xerogels that combine the mechanical, thermal, and structural rigidity and stability of inorganic materials with the flexibility and functionality of organic molecules [1]. These properties favor their utilization as chemical and optical sensors [2-7], catalysts [8,9], coatings [10-14], chromatographic agents [15,16], nanoprobes, and photovoltaic cells $[17,18]$, among others.

The most widely adopted approach to hybrid xerogel synthesis is the sol-gel method [19], using either (i) "silane coupling agents" to provide a functional surface group that can be substituted or act as a bridge to other structural units $[3,10,11,15]$ or (ii) co-condensation 
reactions or condensation between monomers of silicon tetraalkoxides (e.g., tetramethoxyor tetraethoxysilane (TMOS, TEOS)) and one or more mono-, di-, or tri-alkylalkoxysilanes $\left(\mathrm{R}_{\mathrm{x}} \mathrm{Si}\left(\mathrm{OR}^{\prime}\right)_{4-\mathrm{x}}\right)$. This procedure yields hybrid silicon materials based on a silica matrix with organic groups that modify the network, permitting the production of materials with specifically designed chemical and textural properties in a single process [20-22]. The incorporation of organic groups is known to promote the formation of ordered domains induced by intermolecular forces (e.g., hydrogen bonds, hydrophobic or electrostatic interactions, or $\pi-\pi$ stacking) [23]. Although these forces may be weak at molecular level, they are capable of directing the nanostructuring mechanism at macromolecular level. This approach may offer a simple and efficient option for the preparation of transparent materials with controlled structure and porosity that can also have different morphologies (membranes, monoliths, and fibers, among others) [24]. The structure and texture of materials produced by the sol-gel method are known to be influenced by the molar percentage of $\mathrm{R}_{\mathrm{x}} \mathrm{Si}\left(\mathrm{OR}^{\prime}\right)_{4-\mathrm{x}}[25,26]$, the $\mathrm{pH}$ [27], the proportions of $\mathrm{H}_{2} \mathrm{O}$ /TEOS and EtOH/TEOS [18,26,27], and the curing and drying methods $[28,29]$. Changes in these factors can produce significant variations in the density and porosity of the resulting xerogel. In this way, the properties of these materials can be controlled by acting on their molecular structure and morphology.

In previous studies, the formation of ordered domains in the amorphous structure of hybrid silicon xerogels was evidenced by: (i) a signal in the X-ray diffraction spectra at $2 \theta<10^{\circ}$, (ii) the appearance in the NMR spectra of $T^{2,3}$ structures $\left(\mathrm{T}^{\mathrm{n}}\right.$, notation used for silicon atoms bonded to three oxygen atoms and $\mathrm{Q}^{\mathrm{n}}$, for silicon atoms bonded to four bridged oxygen atoms) [30,31], and (iii) a band at around $1150 \mathrm{~cm}^{-1}$ in the Fouriertransform infrared spectroscopy (FTIR) spectra [20-22]. These observations are consistent with data obtained by mass spectrometry (MS) [21], simulations of the FTIR spectra, and inelastic neutron spectroscopy (INS). We also constructed a theoretical cage model to explain the presence of ordered domains in these materials and increase knowledge of the properties and the processes involved in their formation [32].

The aim of the present study was to determine the influence of the alkyl chain and chlorine atom on the morphological and textural properties of various hybrid materials produced by co-condensation. For this purpose, three new series of organochlorinated xerogels were prepared and characterized using TEOS and a chloroalkyltriethoxysilane (CIRTEOS; $\mathrm{R}=$ methyl $[\mathrm{M}]$, ethyl $[\mathrm{E}]$, or propyl $[\mathrm{P}]$ ) at different molar ratios. These chlorinated precursors have been used as silane coupling agents or in the preparation of polyhedral oligomeric silsesquioxanes (POSS) [33-35]; however, to our best knowledge, they have not been studied in co-condensation with tetraalkoxysilanes. Development of the structure and morphology of these materials was characterized by ${ }^{29} \mathrm{Si}$ NMR (Nuclear Magnetic Resonance), XRD (X-ray Diffraction), FTIR (Fourier-Transform Infrared Spectroscopy), helium pycnometry, FE-SEM (Field-Emission Scanning Electron Microscopy), and $\mathrm{N}_{2}$ and $\mathrm{CO}_{2}$ adsorption. The influence of the halogen was also explored by comparison with results previously obtained for analogous alkyl xerogels (RTEOS:TEOS) [20-22]. The ultimate application of these materials is to use them as coatings for optical fiber sensors, for which a labile and specific interaction with the analyte is necessary, hence the importance of increasing knowledge on their properties to be able to develop siliceous materials with tailored properties and porosities.

\section{Materials and Methods}

Three series of hybrid xerogels were synthesized by the sol-gel method at $\mathrm{pH}=4.5$ [36] using two precursors at different molar ratios, TEOS:CIMTEOS, TEOS:CIETEOS, and TEOS:CIPTEOS $($ TEOS $=$ tetraethoxysilane, CIMTEOS $=($ chloromethyl $)$ triethoxysilane, ClETEOS = (2-chloroethyl)triethoxysilane, and CIPTEOS = (3-chloropropyl)triethoxysilane), maintaining a constant precursor:ethanol:water ratio of 1:4.75:5.5 [27,37]. 


\subsection{Materials}

Siliceous precursors TEOS (purity > 99\%), CIMTEOS (purity > 95\%), and CIPTEOS (purity $>95 \%$ ) were supplied by Sigma-Aldrich (St. Louis, MO, USA), and ClETEOS (purity $>95 \%$ ) was supplied by Flurochem (Glossop, Derbyshire, UK). Absolute ethanol (GPRA analysis) and $\mathrm{HCl}$ were purchased from Merck (Darmstadt, Germany). All of these chemicals were used without further purification.

\subsection{Synthesis of Silicon Hybrid Xerogels}

First, the siliceous precursors TEOS and CIRTEOS (CIMTEOS, CIPTEOS, or CIETEOS) were mixed in a $30 \mathrm{~mL}$ container with diameter of $3.5 \mathrm{~cm}$ and threaded plastic lid (Scharlab, Barcelona, Spain). Absolute ethanol (as solvent) and Milli-Q grade water were added dropwise under magnetic stirring to facilitate miscibility, using an automatic burette (Tritino mod. 702 SM, Metrohm, Herisau, Switzerland). The solution $\mathrm{pH}$ was adjusted to 4.5 with $0.05 \mathrm{M} \mathrm{HCl}$. The containers were placed in a reciprocating shaker (SO1- Bibby Stuart, Stone, UK) and kept in a thermostatized oven at $60^{\circ} \mathrm{C}$ (J.P. Selecta S.A., Barcelona, Spain) until gelling. The materials were considered gelled if their shape did not change when the container was tilted.

After gelling, the alcogels were cured with $5 \mathrm{~mL}$ of ethanol for 1 week at room temperature with the lid closed. Next, the containers were covered with parafilm ${ }^{\mathrm{TM}}$, which was punctured with small holes to facilitate solvent evaporation, and were then dried at room temperature and atmospheric pressure [28]. Some samples developed cracks and fractures during the drying process, attributable to stress generated by capillary forces within the pores [38].

\subsection{Characterization of Silicon Hybrid Xerogels}

The amorphous nature of hybrid xerogels means that numerous techniques must be applied to characterize their structure and properties [39].

${ }^{29} \mathrm{Si}$ Cross Polarization Magic-Angle Spinning (CP MAS) solid-state NMR was recorded on a Bruker AV-400 MHz spectrometer (Billerica, MA, USA) operating at $79.5 \mathrm{MHz}$ for ${ }^{29} \mathrm{Si}$. Spectra were obtained at room temperature, giving chemical shifts in parts per million relative to tetramethylsilane, using ${ }^{1} \mathrm{H}$ decoupling, a rotation frequency of $5 \mathrm{kHz}$, and 800 scans per spectrum. The classical notation in ${ }^{29} \mathrm{Si}$ NMR studies was employed, i.e., $\mathrm{T}$ for silicon atoms bound to three oxygen atoms capable of forming siloxane bridges (from precursors), and $\mathrm{Q}$ for silicon atoms bound to four oxygen atoms capable of forming siloxane bridges (from TEOS). $T$ and $Q$ notations were completed with superscript $i\left(T^{i}, i=0,1,2\right.$ or $3 ; Q^{i}$, $\mathrm{i}=0,1,2,3$ or 4 ) for the number of $\mathrm{Si}-\mathrm{O}-\mathrm{Si}$ bridges in each silicon atom [40].

X-ray diffraction patterns were obtained at room temperature, using a PANalytical Empyrean XRD instrument (Empyrean, Almelo, The Netherlands) with copper rotating anode and graphite monochromator (at $45 \mathrm{kV}$ and $40 \mathrm{~mA}$ ) to select the $\mathrm{CuK}_{\alpha 1 / 2}$ wavelength at $1.54 \mathrm{~nm}$. Measurements were performed in a stepped scan mode of $2 \leq 2 \theta \leq 50^{\circ}$ in steps of $0.013^{\circ}$ at a rate of 0.5 steps s $^{-1}$ [41].

$\mathrm{N}_{2}$ and $\mathrm{CO}_{2}$ adsorption isotherms (at -196 and $0{ }^{\circ} \mathrm{C}$, respectively) were determined with a volumetric adsorption system (ASAP2020, Micromeritics, Norcross, GA, USA), weighing approximately $150 \mathrm{mg}$ of sample into a straight-walled Pyrex glass tube followed by degassing at $150^{\circ} \mathrm{C}$ for $\leq 6 \mathrm{~h}$ with a residual vacuum of $<0.66 \mathrm{~Pa}$. Analysis time ranged from 14 to $55 \mathrm{~h}$ for $\mathrm{N}_{2}$ adsorption and from 2.5 to $9 \mathrm{~h}$ for $\mathrm{CO}_{2}$ adsorption). For $\mathrm{N}_{2}$ adsorption, the sample tube was covered with an isothermal jacket and immersed in a Dewar with liquid nitrogen $\left(-196^{\circ} \mathrm{C}\right)$. For $\mathrm{CO}_{2}$ adsorption, the tube was placed in a thermostatized recirculation bath (PolyScience, Niles, IL, USA) at $0{ }^{\circ} \mathrm{C}$, using ethylene glycol as a refrigerant. The recorded adsorption data were analyzed with the Microactive (version 4.06) software of the system, adjusting the parameters as appropriate for each model. Specific surface areas were calculated using two techniques: (i) the Brunauer-Emmett-Teller (BET) model (a $a_{\mathrm{BET}}$ ) and (ii) the Dubinin-Radushkevich (DR) method, applying a molecular section of $0.17 \mathrm{~nm}^{2}$ to $\mathrm{CO}_{2}\left(\mathrm{a}_{\mathrm{DR}}\right)$ [42]. Pore volumes were defined by their diameter $(\varnothing)$ : (i) The volume of 
micropores $(\varnothing \leq 2 \mathrm{~nm})$ was obtained from the DR method ( $\mathrm{V}_{\text {micro(N2) }}$ and $\left.\mathrm{V}_{\text {micro(CO2) }}\right)$, (ii) the volume of mesopores $(2<\varnothing \leq 50 \mathrm{~nm})$ was calculated by abstracting the amount of $\mathrm{N}_{2}$ adsorbed at $\mathrm{p} / \mathrm{p}^{\mathrm{o}}=0.3$ from that adsorbed at $\mathrm{p} / \mathrm{p}^{\mathrm{o}}=0.8\left(\mathrm{~V}_{\text {meso(N2) }}\right)$, and (iii) the total volume $\left(\mathrm{V}_{\text {Total(N2) }}\right)$ was considered as the amount of $\mathrm{N}_{2}$ adsorbed at $\mathrm{p} / \mathrm{p}^{\mathrm{o}}=0.95$. Liquid densities of the adsorbates were obtained from the literature $\left(0.808 \mathrm{~g} \mathrm{~cm}^{-3}\right.$ for $\mathrm{N}_{2}$ and $1.023 \mathrm{~g} \mathrm{~cm}^{-3}$ for $\left.\mathrm{CO}_{2}\right)[43,44]$. Porosity distributions were determined according to density-functional theory (DFT) using SAIEUS software and applying the "carbon-N2-77, 2D-NLDFT heterogeneous Surface" model for $\mathrm{N}_{2}$ adsorption and the "carbon-CO2-273, 2D-NLDFT Het Surface, pp max $=10 \mathrm{~atm}$ " model for $\mathrm{CO}_{2}$ adsorption. Mean pore sizes were further determined by applying the Barrett-Joyner-Halenda (BJH) method to the desorption curves, using a Kruk-Jaroniec-Sayari correction and thickness curve.

Skeletal density was measured using a helium pycnometer (AccuPyc 1330, Micromeritics, Norcross, GA, USA), performing a routine calibration before analyses (20 purges and 10 measurements). The sample was weighed into a $1 \mathrm{~cm}^{3}$ cell, which was filled to the maximum possible to reduce measurement inaccuracies caused by dead volumes. Each sample was analyzed using 10 purges and 5 measurements.

Field-emission scanning electron microscopy (FE-SEM) provides high-resolution images of sample surfaces, and energy-dispersive X-ray spectroscopy (EDX) reveals the surface distribution of the atoms. Micrographs were obtained with a Carl Zeiss SMT field emission scanning electron microscope (Carl Zeiss SMT, Oberkochen, Germany), at $200 \mathrm{kV}$.

Infrared spectra were obtained using a FTIR spectrometer (Jasco mod. 4700, Japan), yielding the following two spectral ranges with two different sample concentrations in order to facilitate band comparisons: (i) $4000-2200 \mathrm{~cm}^{-1}$, recorded with $2 \mathrm{mg}$ of sample dispersed in $200 \mathrm{mg} \mathrm{KBr}$ to examine in greater detail the region where hydroxyl and $\mathrm{C}-\mathrm{H}$ bonds appear and (ii) $2200-400 \mathrm{~cm}^{-1}$, recorded with $0.6 \mathrm{mg}$ of sample in $200 \mathrm{mg} \mathrm{KBr}$ to avoid saturation of the $\mathrm{Si}-\mathrm{O}-\mathrm{Si}$ asymmetric stretching signal [45]. Tablets were dried overnight in an oven at $115{ }^{\circ} \mathrm{C}$ under vacuum to minimize the amount of water adsorbed. Spectra were recorded using 25 scans and a resolution of $4 \mathrm{~cm}^{-1}$.

\section{Results}

\section{1. ${ }^{29}$ Si Nuclear Magnetic Resonance (NMR)}

${ }^{29} \mathrm{Si}$ NMR spectra were obtained to study the effect of chloroalkyl precursors on the relative abundance of silicon species in hybrid xerogels. In all cases, they showed the characteristic bands of the different species of silicon that can be found in this type of material, represented in Figure 1a.
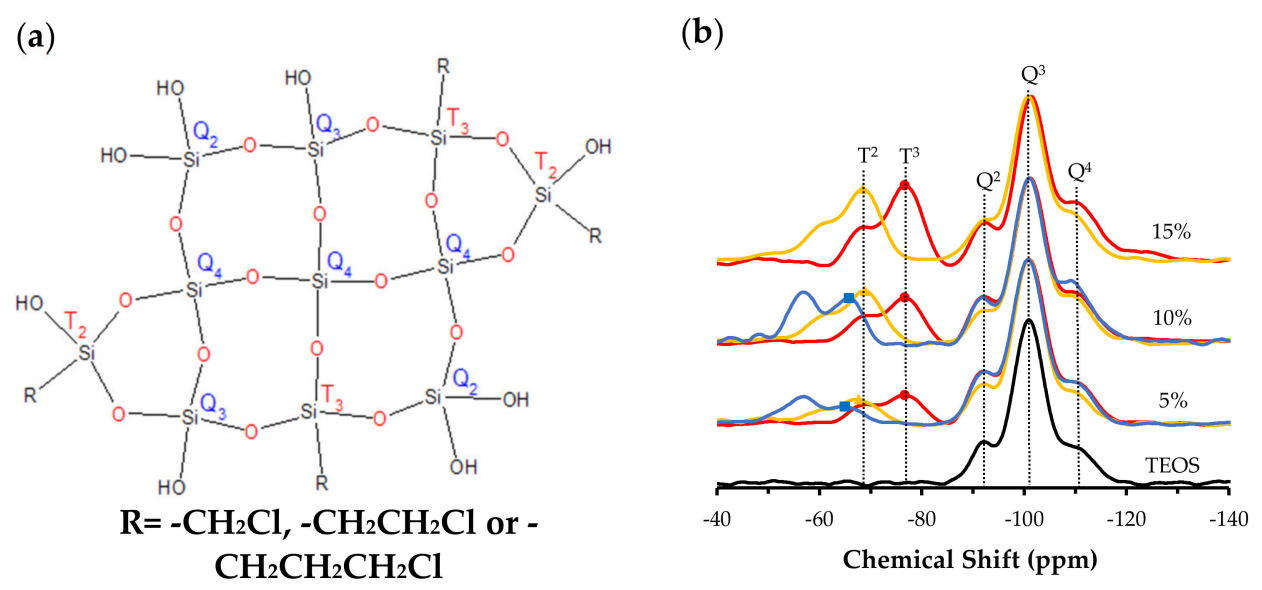

Figure 1. (a) Silicon environments present in chloroalkyltriethoxysilane (CIRTEOS):tetraethoxysilane (TEOS) xerogels, and (b) normalized ${ }^{29} \mathrm{Si}$ NMR spectra of the hybrid xerogels synthesized with $5 \%, 10 \%$, and $15 \%$ of CIRTEOS (chloromethyltriethoxysilane (CIMTEOS) $(\bullet)$, chloroethyltriethoxysilane (ClETEOS) $(\triangle)$, and chloropropyltriethoxysilane (CIPTEOS) ( $\square)$ ). 
Figure $1 \mathrm{~b}$ depicts ${ }^{29} \mathrm{Si}$ NMR spectra for the three series of CIRTEOS:TEOS xerogels, normalized with respect to the $\mathrm{Q}^{3}$ signal, which was always the most intense signal and corresponds to the dominant species in these materials synthesized in acid media. $\mathrm{Q}^{1}$ and $\mathrm{T}^{1}$ signals are not detected [20], and the proportions of $\mathrm{T}^{2}$ and $\mathrm{T}^{3}$ species vary according to the precursors. Thus, $\mathrm{T}^{3}$ species are more abundant than $\mathrm{T}^{2}$ species at all molar percentages in xerogels prepared with CIMTEOS and CIETEOS, indicating that these xerogels are preferably formed by the most condensed species. Spectra for the series prepared with CIPTEOS show a predominance of $\mathrm{T}^{2}$ species, implying that more silicon atoms are partially condensed and attached to hydroxyl groups. Spectra for the $Q$ species reveal a decrease in $\mathrm{Q}^{3}$ and $\mathrm{Q}^{2}$ species with an increase in the molar percentage of chlorinated precursor.

Figure 2 depicts the relative abundance of species detected in the spectra for the three series of hybrid xerogels CIRTEOS:TEOS. It shows the time course of the total proportion of $\mathrm{Q}\left(\mathrm{Q}^{2}+\mathrm{Q}^{3}+\mathrm{Q}^{4}\right)$ and $\mathrm{T}\left(\mathrm{T}^{2}+\mathrm{T}^{3}\right)$ species as a function of the percentage of CIRTEOS and the time course of each individual species. It can be observed that $\mathrm{Q}^{2}$ and $\mathrm{Q}^{3}$ species always decrease with increased molar percentage of the chlorinated precursor, while the results for $\mathrm{Q}^{4}$ differ according to the precursor used, with a lower abundance in the CIMTEOS series and a slightly higher abundance in the CIPTEOS series. Figure 2 also shows that $\mathrm{T}^{3}$ species predominate over $\mathrm{T}^{2}$ species in the CIMTEOS and CIETEOS series, whereas $\mathrm{T}^{2}$ species predominate in the CIPTEOS series. This is attributable to the steric hindrance exerted by the chloropropyl chain in the condensation reactions, hampering complete condensation around the silicon atoms. The chloropropyl chain also influences the surface charge of the colloids and generates repulsion between them, consistent with the exponential increase in gelation times of this series at the highest molar percentages (Table S1).

(a)

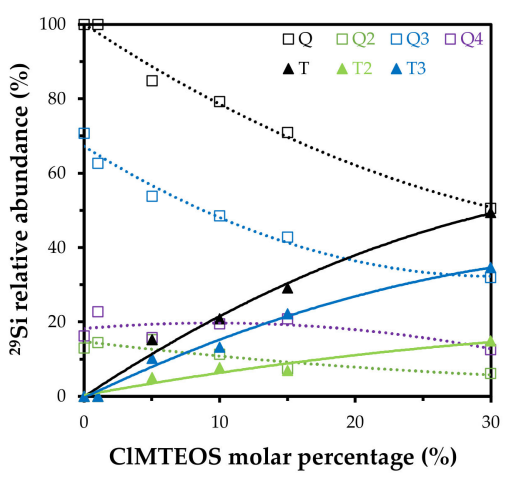

(b)

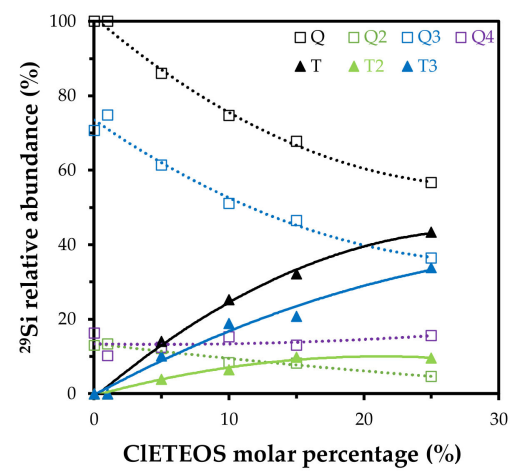

(c)

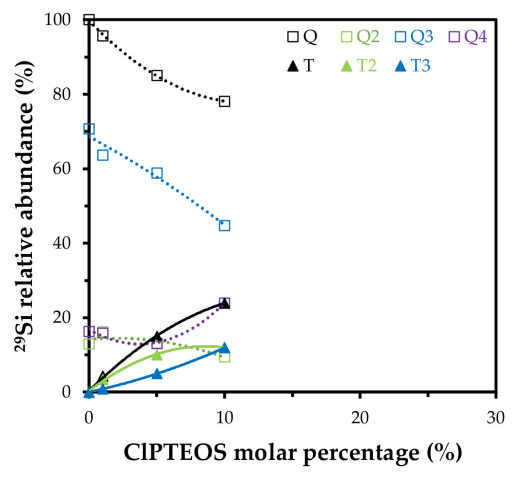

Figure 2. Variation in the relative abundance of the condensed species of $\mathrm{Si}$ with respect to percentage CIRTEOS obtained by integrating the ${ }^{29} \mathrm{Si}$ NMR spectra for: (a) CIMTEOS, (b) ClETEOS, and (c) CIPTEOS.

Chen et al. reported that $\mathrm{T}^{3}$ and $\mathrm{Q}^{4}$ species are predominant in POSS synthesized with CIMTEOS [35]. In the present study, $\mathrm{T}^{3}$ species are associated with rings formed by cyclic tetramers of $(\mathrm{SiO})_{4}$ that build $\mathrm{T}_{8}$ cages, while $\mathrm{Q}^{4}$ would be the silicon atoms at the vertex that bind $\mathrm{T}_{8}$ structures together. The minor signal detected in the POSS, $\mathrm{T}^{2}$, is related to the presence of partially open cages $\left(T_{7}\right)$. The proportion of $Q$ species has also been associated with the FTIR spectra, with reports that $\mathrm{Q}^{2}, \mathrm{Q}^{3}$, and $\mathrm{Q}^{4}$ species present their asymmetric $\mathrm{Si}-\mathrm{O}-\mathrm{Si}$ stretching vibration mode at different frequencies (1000-1030, 1100 , and $1150-1200 \mathrm{~cm}^{-1}$, respectively) $[46,47]$ and that the aforementioned polycyclic structures $\left((\mathrm{SiO})_{4}\right.$ and $\mathrm{T}_{8}$ cages) are related to bands at 1090 and $1150 \mathrm{~cm}^{-1}$, respectively [48]. It can therefore be concluded that the presence of these structures in the materials is consistent with the increase in $\mathrm{T}^{3}, \mathrm{Q}^{3}$, and $\mathrm{Q}^{4}$ species when the amount of precursor is larger and with the shoulder at $1150 \mathrm{~cm}^{-1}$ observed in the FTIR spectra (Figure S1).

Table 1 exhibits the chemical shifts for the different silicon atoms of each hybrid xerogel, showing that $\mathrm{T}$ and $\mathrm{Q}$ signals are not affected in any series by the increase in molar percentage of CIRTEOS or RTEOS, because there is no significant change in the 
silicon environment. However, a marked shift in T signals is observed in the comparison of different series with the same percentage of precursor. This is attributable to a shielding effect in which the organic precursor acts by adding or removing charge density to the silicon atom, thereby shifting the signal to a higher or lower field $[49,50]$. The chlorine atom removes charge density, reducing the donor capacity of the alkyl chains and increasing the positive charge of the silicon atom, and this effect is reflected in the shift of its signal to lower ppm. Likewise, the further the chlorine is from the silicon atom, the lesser is the shift of the signal. This trend is readily observed by comparing the average $\mathrm{T}^{3}$ chemical shift between the chloroalkyl and the alkyl series: (i) $-12.2 \mathrm{ppm}$ when chlorine is in carbon $\alpha$ position (MTEOS vs. CIMTEOS), (ii) $-4.4 \mathrm{ppm}$ when it is in $\beta$ position (ETEOS vs. CIETEOS), and (iii) $-0.45 \mathrm{ppm}$ when it is in $\gamma$ position (PTEOS vs. CIPTEOS).

Table 1. Signals from the ${ }^{29} \mathrm{Si}$ NMR spectra of the hybrid xerogels chloroalkyltriethoxysilane (CIRTEOS):tetraethoxysilane (TEOS) and alkyltriethoxysilane (RTEOS): tetraethoxysilane (TEOS) ( $\mathrm{R}=$ methyl, ethyl, and propyl) [20-22].

\begin{tabular}{|c|c|c|c|c|c|c|}
\hline \multirow{2}{*}{ Precursor } & \multirow{2}{*}{$\begin{array}{c}\text { Precursor } \\
\text { Molar Percentage } \\
(\%)\end{array}$} & \multicolumn{5}{|c|}{${ }^{29} \mathrm{Si} \mathrm{RMN}$ (ppm) } \\
\hline & & $\mathrm{T}^{2}$ & $\mathrm{~T}^{3}$ & $\mathrm{Q}^{2}$ & $\mathrm{Q}^{3}$ & $\mathrm{Q}^{4}$ \\
\hline \multirow{3}{*}{ CIMTEOS } & 5 & -68.5 & -76.6 & -92 & -100.9 & -110.4 \\
\hline & 10 & -68.9 & -76.8 & -91.8 & -101.0 & -110.1 \\
\hline & 15 & -68.3 & -76.7 & -92.9 & -101.3 & -110.4 \\
\hline \multirow{3}{*}{ CIMTEOS } & 5 & -60.2 & -67.7 & -91.7 & -100.8 & -109.7 \\
\hline & 10 & -60.3 & -68.8 & -91.7 & -100.8 & -109.7 \\
\hline & 15 & -60.3 & -68.7 & -91.9 & -100.9 & -109.5 \\
\hline \multirow{2}{*}{ CIPTEOS } & 5 & -57.0 & -65.0 & -91.6 & -100.8 & -110.3 \\
\hline & 10 & -57.4 & -65.5 & -91.9 & -100.7 & -109.6 \\
\hline \multirow{3}{*}{ MTEOS } & 30 & -54.8 & -63.1 & -91.7 & -101.1 & -110.9 \\
\hline & 70 & -56.3 & -64.6 & a & -100.9 & -109.6 \\
\hline & 100 & -57.0 & -65.8 & a & $\mathrm{a}$ & a \\
\hline \multirow{3}{*}{ ETEOS } & 10 & -54.6 & -63.2 & -92.5 & -101.7 & -110.7 \\
\hline & 30 & -55.7 & -63.8 & -92.3 & -101.3 & -109.9 \\
\hline & 60 & -56.4 & -65.0 & $\mathrm{a}$ & -101.9 & -110.0 \\
\hline \multirow{3}{*}{ PTEOS } & 10 & -56.4 & -64.1 & -92.2 & -100.9 & -110.2 \\
\hline & 30 & -56.1 & -64.6 & -90.9 & -100.3 & -109.4 \\
\hline & 60 & -56.8 & -65.7 & a & -101.4 & -110.4 \\
\hline
\end{tabular}

a-Non detected.

\subsection{X-Ray Diffraction (XRD)}

Figure 3 displays the XRD spectra of the xerogels synthesized with CIMTEOS, ClETEOS, and CIPTEOS. The diffraction pattern shows a broad signal at around $2 \theta=24^{\circ}$, characteristic of amorphous silica. This signal corresponds to the distance between silicon atoms connected by siloxane bonds [49]. It can be observed that the intensity of this signal is reduced with an increased molar percentage of the precursor and that another signal arises with higher molar percentage of CIMTEOS and CIPTEOS $(30 \%$ and $10 \%$, respectively) at $2 \theta<10^{\circ}$. The behavior of the CIETEOS series is different, observing the presence of this signal at the lowest molar percentage $(1 \%)$ and an increase in its intensity with a larger amount of precursor. The $2 \theta<10^{\circ}$ signal is associated with the formation of ordered structures composed of $\mathrm{T}_{8}$ cages or ladders, which are, in turn, related to lamellar morphologies [51-53]. The distances calculated from this maximum correspond to the distance between the organic substituents in these structures [32]. The three series show this band at lower molar percentages in comparison to those previously observed for their alkyl equivalents, being detected in 70\% of MTEOS, 30\% of ETEOS, and 10\% of PTEOS series [20-22]. This indicates a higher tendency for the chloroalkyl precursors to form ordered domains in the amorphous matrix. There is also a broad low-intensity signal at 
$2 \theta \sim 45^{\circ}$. According to Bragg's law, these bands correspond to replicas of the signal at $2 \theta=24^{\circ}$, which supports the presence of local periodicity in the silica matrix.

(a)

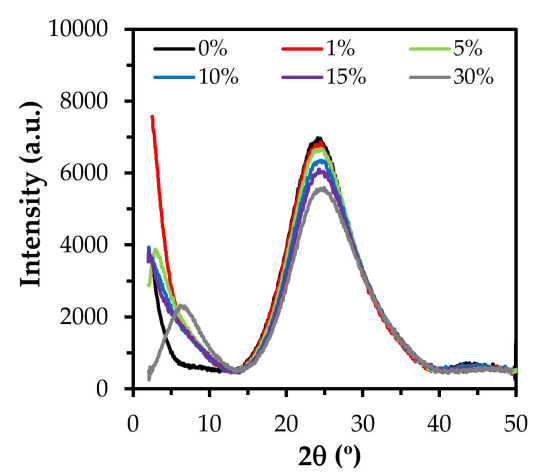

(b)

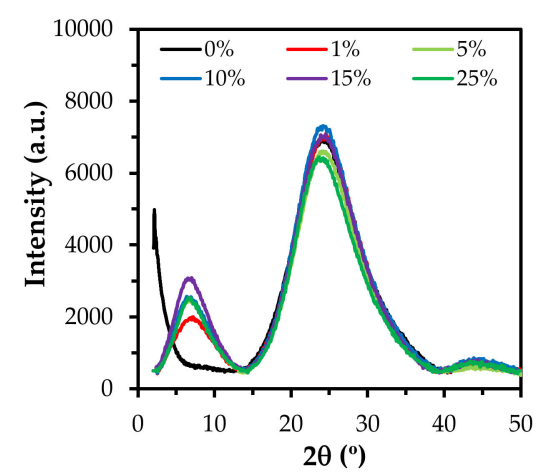

(c)

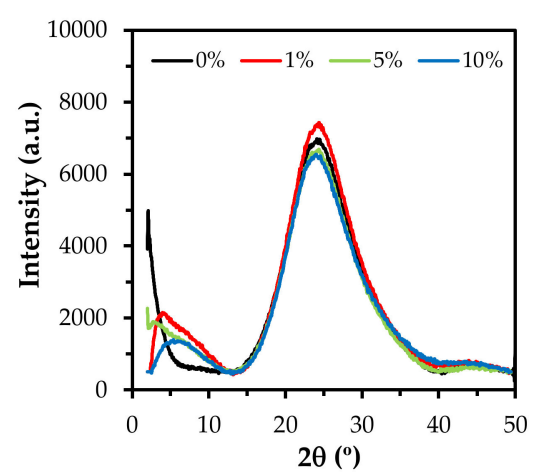

Figure 3. X-ray diffraction patterns of the hybrid xerogels CIRTEOS:TEOS at different molar percentages: (a) CIMTEOS, (b) ClETEOS, and (c) CIPTEOS.

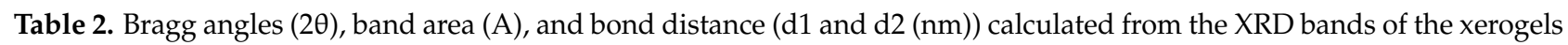
synthesized with different precursors and molar percentages.

\begin{tabular}{|c|c|c|c|c|c|c|c|}
\hline \multirow{2}{*}{ Precursor } & \multirow{2}{*}{$\begin{array}{c}\text { CIRTEOS } \\
\text { Molar Percentage }(\%)\end{array}$} & \multicolumn{3}{|c|}{ Peak $2 \theta<10^{\circ}$} & \multicolumn{3}{|c|}{ Peak $10^{\circ}<2 \theta<30^{\circ}$} \\
\hline & & $2 \theta_{1}\left({ }^{\circ}\right)$ & $\mathbf{A}_{1}$ & $\mathrm{~d}_{1}(\mathrm{~nm})$ & $2 \theta_{2}\left({ }^{\circ}\right)$ & $\mathrm{A}_{2}$ & $\mathrm{~d}_{2}(\mathrm{~nm})$ \\
\hline TEOS & 0 & $\mathrm{a}$ & $\mathrm{a}$ & $\mathrm{a}$ & 24.16 & 68,812 & 0.368 \\
\hline \multirow{5}{*}{ CIMTEOS } & 1 & a & a & a & 24.26 & 66,451 & 0.367 \\
\hline & 5 & a & $\begin{array}{l}\mathrm{a} \\
\mathrm{a}\end{array}$ & a & 24.30 & 65,847 & 0.366 \\
\hline & 10 & a & a & a & 24.54 & 62,627 & 0.363 \\
\hline & 15 & a & a & a & 24.42 & 60,377 & 0.365 \\
\hline & 30 & 6.52 & 10,217 & 1.35 & 24.78 & 56,217 & 0.359 \\
\hline \multirow{5}{*}{ CIMTEOS } & 1 & 7.17 & 8594 & 1.23 & 24.56 & 68,577 & 0.362 \\
\hline & 5 & 6.92 & 15,879 & 1.28 & 24.30 & 74,258 & 0.366 \\
\hline & 10 & 6.76 & 16,568 & 1.31 & 24.14 & 81,785 & 0.369 \\
\hline & 15 & 6.76 & 19,509 & 1.31 & 24.22 & 78,157 & 0.367 \\
\hline & 25 & 6.76 & 15,780 & 1.31 & 23.90 & 71,722 & 0.372 \\
\hline \multirow{3}{*}{ CIPTEOS } & 1 & a & a & $\mathrm{a}$ & 24.22 & 73,819 & 0.367 \\
\hline & 5 & a & a & $\mathrm{a}$ & 23.98 & 65,782 & 0.371 \\
\hline & 10 & 5.80 & $\stackrel{a}{5514}$ & 1.52 & 24.06 & 66,143 & 0.370 \\
\hline
\end{tabular}

a-Non detected.

Table 2 displays the angles of each signal $(2 \theta)$, the area of the peaks, and the $\mathrm{Si}-\mathrm{O}-\mathrm{Si}$ bond distances. It shows the shift of the amorphous silica signal $\left(2 \theta \sim 24^{\circ}\right)$ as a function of the precursor and its molar percentage. There is a shift to larger angles in the CIMTEOS series, which results in a shortening of the $\mathrm{Si}-\mathrm{O}-\mathrm{Si}$ bond distance $(0.368 \mathrm{~nm}$ for $0 \%$ and $0.359 \mathrm{~nm}$ for $30 \%$ ), whereas there is a shift to smaller angles in the CIETEOS and CIPTEOS series, resulting in longer bond distances $(0.372 \mathrm{~nm}$ for $25 \%$ CIETEOS and $0.370 \mathrm{~nm}$ for $10 \%$ CIPTEOS). These modifications of bond distances are attributable to inductive and steric effects generated by the chloroalkyl substituents of the precursors. The shorter bond distances for the CIMTEOS series result from the predominance of the inductive effect of the chlorine atom, which removes electron density from the silicon atom and therefore polarizes the adjacent $\mathrm{Si}-\mathrm{O}$ bond. On the contrary, in CIETEOS and CIPTEOS series, the effect of the alkyl chain predominates over the inductive effect of the chlorine atom, thus elongating the adjacent $\mathrm{Si}-\mathrm{O}$ bond as occurred with their non-chlorinated analogues. 


\subsection{Skeletal Density}

Helium pycnometry reveals the skeletal density of the synthesized xerogels. Figure 4 depicts the variation in skeletal density as a function of the molar percentage of the precursor for the chloroalkyl series (Figure 4a) and for the analogous alkyl series prepared in previous studies (Figure $4 \mathrm{~b}$ ). The density of the chloroalkyl xerogels decreases with a greater proportion of the precursor, because the precursor blocks one of the hydrolysis and condensation positions, reducing the degree of cross-linking. Another influencing factor is the nature of the substituent, observing a lower skeletal density with longer alkyl chain due to greater steric hindrance. In the previously studied alkyl xerogels, the XRD spectra show an elongation of the siloxane bonds consistent with the donor effect of the carbon atom directly bound to silicon, leading to lesser compaction and therefore, lower skeletal density [20-22]. In the chloroalkyl series, densities are higher than those of their non-chlorinated analogues at the same molar percentages due to the attractor effect of chlorine. For example, at a molar percentage of $10 \%$, the density value is $1.91 \mathrm{~g} \cdot \mathrm{cm}^{-3}$ for the CIMTEOS xerogel vs. $1.7 \mathrm{~g} \cdot \mathrm{cm}^{-3}$ for the MTEOS xerogel.

(a)

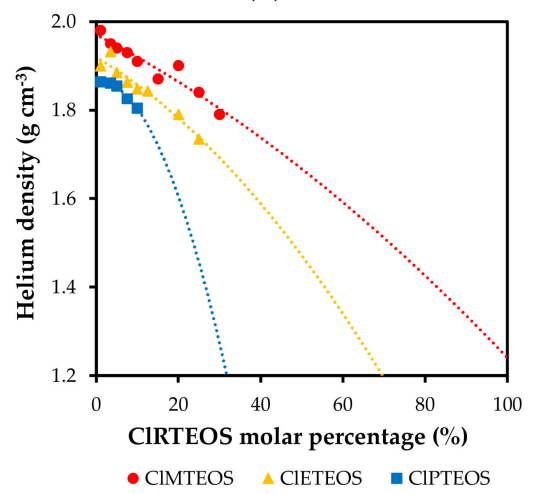

(b)

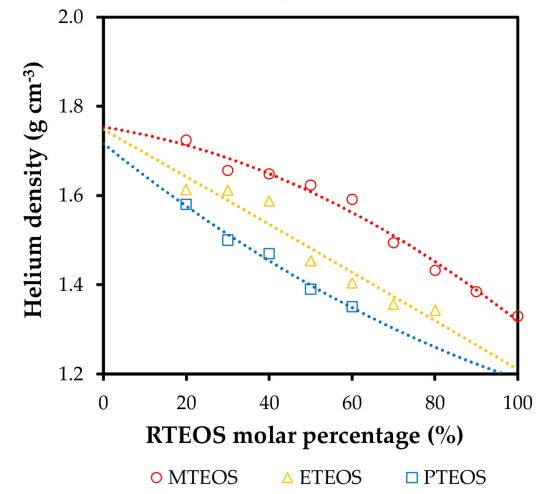

Figure 4. Skeletal density of the materials according to the precursor molar percentage for: (a) CIRTEOS series (CIMTEOS, CIETEOS, and CIPTEOS) and (b) RTEOS series (MTEOS, ETEOS, and PTEOS) in previous studies [20-22]. Reference material density $(100 \%$ TEOS $)=1.96 \mathrm{~g} \cdot \mathrm{cm}^{-3}$.

\subsection{Porous Texture}

3.4.1. Adsorption Isotherms and Textural Properties

The nitrogen adsorption isotherms of the CIRTEOS:TEOS series are exhibited in Figure 5. The isotherm of the reference material has a flat knee (Type I(b) isotherm), an adsorption branch with a positive slope, and a hysteresis loop in the desorption branch (H2 (a)), typical of type IV(a) isotherms. It is therefore a material with a mixed Type I(b)-IV(a) isotherm, indicating micro-mesoporosity [54].

With respect to the reference material, the isotherms of the hybrid xerogels prepared in this study show that they adsorbed a smaller amount of $N_{2}$, gradually becoming more microporous. The knees are sharper, the plateaus are practically parallel to the abscissa axis, and the hysteresis loop disappears. Figure 5 depicts the $\mathrm{N}_{2}$ isotherms of the three series of chloroalkyl xerogels. In the CIMTEOS series (Figure 1a), Type IV isotherms become Type $\mathrm{I}(\mathrm{b})$ and I(a) with increased molar percentage of the precursor ( $10 \%$ and $30 \%$, respectively), and $\mathrm{N}_{2}$ adsorption ceases when the highest molar percentage is reached (35\%) (Table 3). In contrast, Figure 5a depicts the striking observation of a Type IV(a) isotherm for the material containing $1 \%$ of CIMTEOS, showing a similar knee but wider hysteresis loop in comparison to the reference material (Type H1). Dudás et al. prepared hybrid xerogels with low proportions of MTEOS and also observed increased $\mathrm{N}_{2}$ adsorption, associated with the transition from cone to ink-bottle shaped pores that is responsible for the Type $\mathrm{H} 1$ hysteresis loop [55]. The CIETEOS series (Figure 5b) has a type I(a) isotherm at a precursor molar percentage of $1 \%$, whereas $\mathrm{N}_{2}$ adsorption is very low at higher percentages and ceases at 
$12.5 \%$. The CIPTEOS series (Figure $5 c$ ) changes from Type I(b) at a percentage of $1 \%$ to Type $\mathrm{I}(\mathrm{a})$ at percentages up to $10 \%$, with a cessation of adsorption at higher percentages, as in the case of the CIETEOS xerogels. The isotherms in Figure 5 are depicted on a semi-logarithmic scale in Figure S2 (Supplementary Materials) to visualize more clearly the development of the microporosity at higher molar percentages of the precursor. Hence, the incorporation of chlorinated precursors into the structure of TEOS modifies its porosity, reducing the size, volume, and shape of the pores in the following order: CIETEOS > CIPTEOS > CIMTEOS.

At least two adsorbates are required to characterize the porosity of a material. $\mathrm{N}_{2}$ adsorption $\left(-196{ }^{\circ} \mathrm{C}\right)$ has long been complemented by $\mathrm{CO}_{2}$ adsorption $\left(0^{\circ} \mathrm{C}\right)$, allowing differentiation between microporosity below $0.7 \mathrm{~nm}$ and that above $0.7 \mathrm{~nm}$ (associated with cooperative processes of the adsorbate molecules). The isotherms displayed in Figure 6 show a similar trend for all of the materials, evidencing a lesser adsorption of $\mathrm{CO}_{2}$ at higher molar percentages of the precursor.

(a)

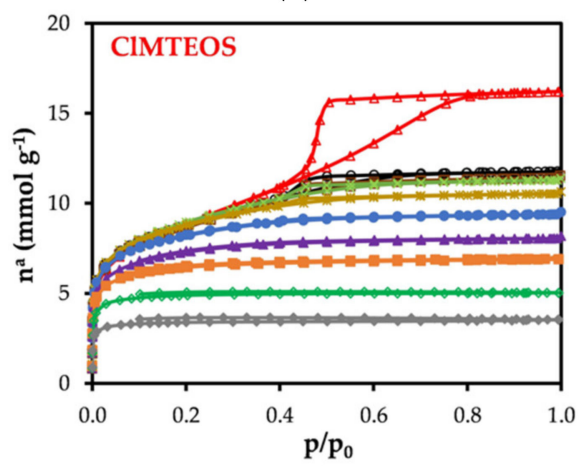

$\begin{array}{lllll}-0 \% & -1 \% & -3.5 \% & -5 \% & -7.5 \% \\ -10 \% & -15 \% & -20 \% & -25 \% & -30 \%\end{array}$ (b)

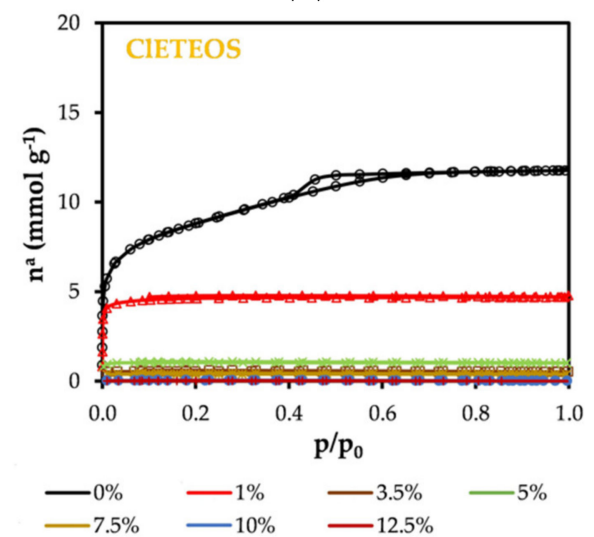

(c)

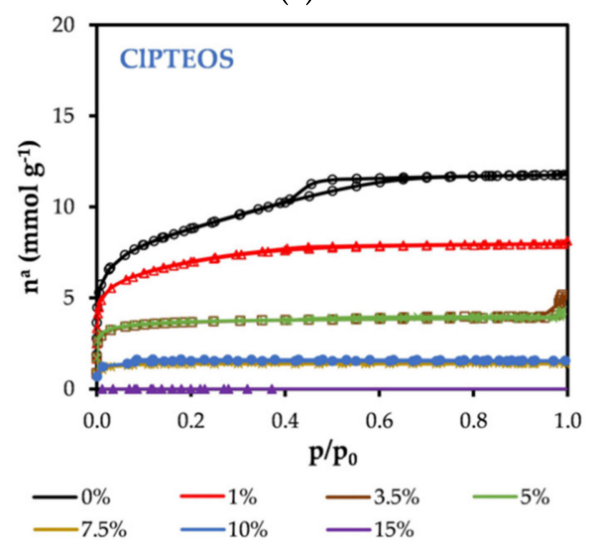

Figure 5. $\mathrm{N}_{2}$ isotherms $\left(-196^{\circ} \mathrm{C}\right)$ of chloroalkyl materials at different molar percentages of: (a) ClMTEOS, (b) ClETEOS, and (c) CIPTEOS.

Table 3 displays the textural values calculated from $\mathrm{N}_{2}$ and $\mathrm{CO}_{2}$ isotherms. A reduction in the specific surface areas $\mathrm{a}_{\mathrm{BET}}\left(\mathrm{N}_{2}\right)$ and $\mathrm{a}_{\mathrm{DR}}\left(\mathrm{CO}_{2}\right)$ can be observed with a higher percentage of CIRTEOS. The pore volume data confirm the essentially microporous nature of the material, given that $\mathrm{V}_{\text {micro }}\left(\mathrm{N}_{2}\right)>\mathrm{V}_{\text {meso }}\left(\mathrm{N}_{2}\right)$, and $\mathrm{V}_{\text {meso }}$ tend towards zero with a higher percentage of the precursor. Notably, the material becomes ultramicroporous at CIETEOS molar percentages above $1 \%$, explaining the lack of $\mathrm{N}_{2}$ adsorption. Higher and more constant adsorption energies (calculated by DR method) were observed for $\mathrm{CO}_{2}$ than for $\mathrm{N}_{2}$, consistent with kinetic restrictions of $\mathrm{N}_{2}$ entry into the narrowest pores. It should be noted that the kinetic energy of $\mathrm{CO}_{2}$ is lower than that of $\mathrm{N}_{2}$ at the higher molar percentages of CIMTEOS $(20 \%$ and $25 \%$ ) and the lowest ratio of CIETEOS (1\%). This is because the $\mathrm{N}_{2}$ retention mechanism within the narrow micropores $\left(\mathrm{r}_{\text {pores }} / \mathrm{r}_{\text {adsorbate }} \sim 1.1\right)$ is based on the overlap of pore wall potentials $(\varnothing<0.7 \mathrm{~nm})$. This behavior was also described in analogous non-chlorinated xerogels [56].

\subsubsection{Porosity Distribution}

Two distinct theoretical approaches were adopted to explore the effect on porosity of the precursors. The BJH method was used to calculate the mean pore size from the desorption branch of the isotherms. Application of this method showed a reduction in mean pore size proportional to the precursor molar percentage (Table 3), from 4.21 to $2.09 \mathrm{~nm}$ of CIMTEOS and from 3.39 to $2.18 \mathrm{~nm}$ of CIPTEOS. In the CIETEOS series, $\mathrm{N}_{2}$ adsorption is only observed at a molar percentage of $1 \%$, and this material has a value of $2.32 \mathrm{~nm}$. 
Table 3. Textural parameters of chloroalkyl materials at different molar percentages.

\begin{tabular}{|c|c|c|c|c|c|c|c|c|c|c|}
\hline \multirow[t]{2}{*}{ Precursor } & \multirow[t]{2}{*}{$\begin{array}{c}\text { CIRTEOS } \\
\text { Molar Percentage (\%) }\end{array}$} & $\begin{array}{l}\mathrm{a}_{\mathrm{BET}} \\
\left(\mathbf{N}_{2}\right)\end{array}$ & $\begin{array}{c}a_{D R} \\
\left(\mathrm{CO}_{2}\right)\end{array}$ & $\begin{array}{c}\mathrm{V}_{\text {micro }} \\
\left(\mathrm{N}_{2}\right)\end{array}$ & $\begin{array}{l}\mathrm{V}_{\text {micro }} \\
\left(\mathrm{CO}_{2}\right)\end{array}$ & $\begin{array}{l}\mathrm{V}_{\text {meso }} \\
\left(\mathrm{N}_{2}\right)\end{array}$ & $\begin{array}{l}\mathrm{V}_{\text {total }} \\
\left(\mathrm{N}_{2}\right)\end{array}$ & $\begin{array}{l}\text { BJH } \\
\text { APS }^{\text {a }}\end{array}$ & $\mathrm{E}_{\mathrm{c}}\left(\mathrm{N}_{\mathrm{b}}\right)$ & $\begin{array}{c}\mathrm{E}_{\mathrm{c}} \\
\left(\mathrm{CO}_{2}\right) \\
\mathrm{b}\end{array}$ \\
\hline & & \multicolumn{2}{|c|}{$\left(\mathrm{m}^{2} \mathrm{~g}^{-1}\right)$} & \multicolumn{4}{|c|}{$\left(\mathrm{cm}^{3} \mathrm{~g}^{-1}\right)$} & $(\mathrm{nm})$ & \multicolumn{2}{|c|}{$\left(\mathrm{KJ} \mathrm{mol}^{-1}\right)$} \\
\hline TEOS & 0 & 697 & 510 & 0.283 & 0.195 & 0.074 & 0.407 & 3.61 & 15.27 & 19.71 \\
\hline \multirow{10}{*}{ CIMTEOS } & 1 & 700 & 465 & 0.289 & 0.178 & 0.210 & 0.560 & 4.21 & 14.27 & 19.77 \\
\hline & 3.5 & 691 & 475 & 0.285 & 0.182 & 0.061 & 0.394 & 3.55 & 14.82 & 18.93 \\
\hline & 5 & 702 & 464 & 0.293 & 0.177 & 0.052 & 0.390 & 3.51 & 14.93 & 19.15 \\
\hline & 7.5 & 693 & 457 & 0.288 & 0.175 & 0.036 & 0.364 & 3.41 & 15.26 & 18.98 \\
\hline & 10 & 662 & 471 & 0.274 & 0.180 & 0.022 & 0.324 & 3.38 & 15.67 & 18.77 \\
\hline & 15 & 591 & 428 & 0.248 & 0.164 & 0.013 & 0.278 & 3.30 & 15.81 & 18.82 \\
\hline & 20 & 534 & 463 & 0.226 & 0.177 & 0.009 & 0.239 & 3.15 & 16.42 & 18.71 \\
\hline & 25 & 422 & 381 & 0.175 & 0.146 & 0.002 & 0.174 & 2.56 & 18.32 & 18.29 \\
\hline & 30 & 294 & 358 & 0.121 & 0.137 & 0.003 & 0.123 & 2.09 & 20.47 & 18.32 \\
\hline & 35 & c & 347 & c & 0.132 & c & c & c & c & 18.04 \\
\hline \multirow{9}{*}{ CIMTEOS } & 1 & 410 & 506 & 0.164 & 0.193 & 0.001 & 0.164 & 2.32 & 22.17 & 20.80 \\
\hline & 3.5 & c & 461 & c & 0.178 & c & c & c & c & 20.05 \\
\hline & 5 & c & 451 & c & 0.172 & c & c & c & c & 20.64 \\
\hline & 7.5 & c & 411 & c & 0.157 & c & c & c & c & 20.25 \\
\hline & 10 & c & 371 & c & 0.142 & c & c & c & c & $\mathrm{d}$ \\
\hline & 12.5 & c & 356 & c & 0.136 & c & c & c & c & 19.69 \\
\hline & 15 & c & 428 & c & 0.164 & c & c & c & c & 19.05 \\
\hline & 20 & c & 351 & c & 0.134 & c & c & c & c & 19.29 \\
\hline & 25 & c & 345 & c & 0.132 & c & c & c & c & 18.55 \\
\hline \multirow{5}{*}{ CIPTEOS } & 1 & 555 & 496 & 0.232 & 0.189 & 0.018 & 0.282 & 3.39 & 16.50 & 19.74 \\
\hline & 3.5 & 312 & 483 & 0.129 & 0.184 & 0.004 & 0.136 & 2.96 & 18.48 & 19.80 \\
\hline & 5 & 318 & 434 & 0.129 & 0.167 & 0.004 & 0.136 & 2.85 & 19.98 & 19.49 \\
\hline & 7.5 & 118 & 433 & 0.050 & 0.165 & 0.000 & 0.048 & 2.09 & 17.37 & 19.72 \\
\hline & 10 & 132 & 359 & 0.056 & 0.137 & 0.000 & 0.053 & 2.18 & 15.72 & 17.69 \\
\hline
\end{tabular}

${ }^{a}$ Average Pore Size; ${ }^{b}$ Characteristic energy from Dubinin-raduskevich; c The samples did not adsorb $\mathrm{N}_{2}$; Not calculated

(a)

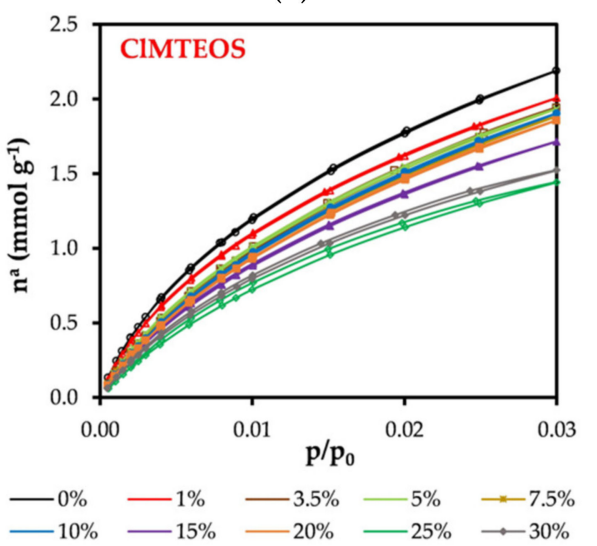

(b)

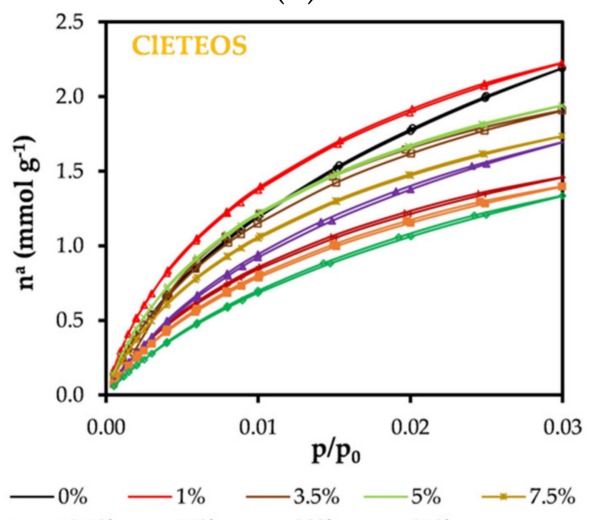

(c)

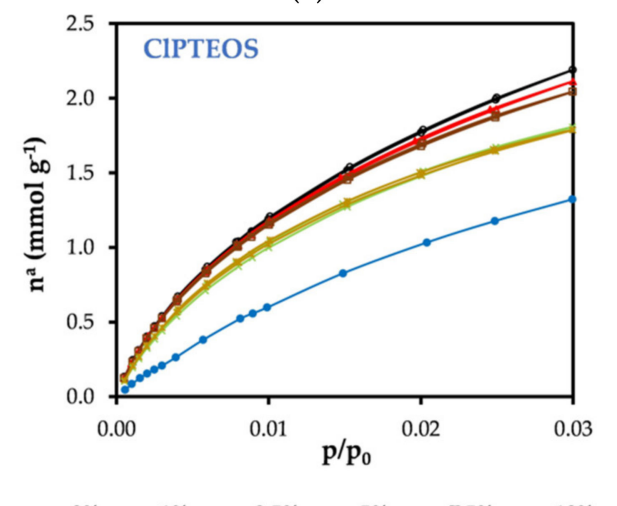

Figure 6. $\mathrm{CO}_{2}$ isotherms $\left(0^{\circ} \mathrm{C}\right)$ of chloroalkyl materials at different molar percentages of: (a) CIMTEOS, (b) ClETEOS, and (c) CIPTEOS.

The DFT was also applied to calculate porosity distributions from $\mathrm{N}_{2}$ and $\mathrm{CO}_{2}$ adsorption data (Figure 7a-f, respectively), showing a similar influence of the precursor in both cases. Thus, $\mathrm{N}_{2}$ isotherm data show a progressive narrowing of the pores and a loss of mesoporosity with a higher percentage of precursor, and the $\mathrm{CO}_{2}$ isotherm data also show 
a sharpening of the micropore distribution. Note should be taken of the aforementioned irregular behaviors of: (i) 1\% CIMTEOS material (Figure 7a), which has an increased pore size in comparison to the reference material, becoming more mesoporous, and (ii) the CIETEOS series (Figure $7 \mathrm{~b}$ ), whose ultramicroporous nature means that pore distribution values can only be obtained for the material with a molar percentage of $1 \%$, observing a gradual loss of porosity with higher percentages of the precursor (Figure 7e).

(a)

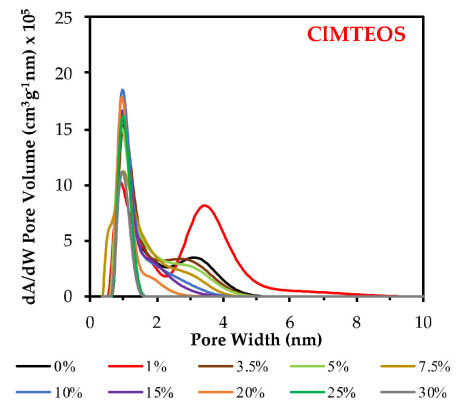

(d)

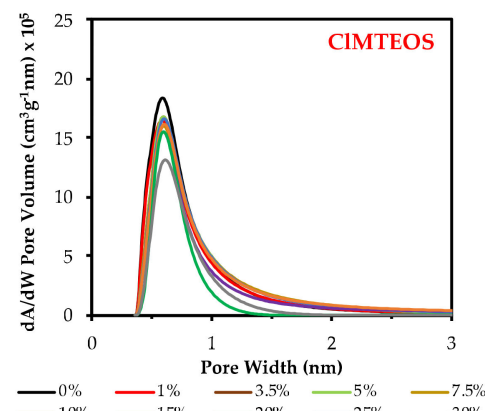

(b)

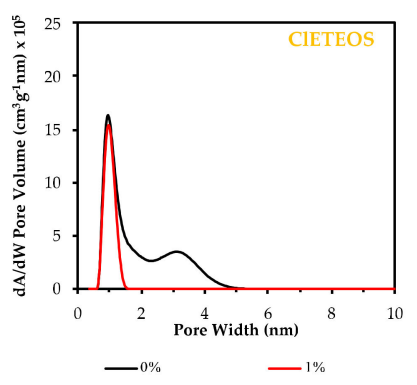

(e)

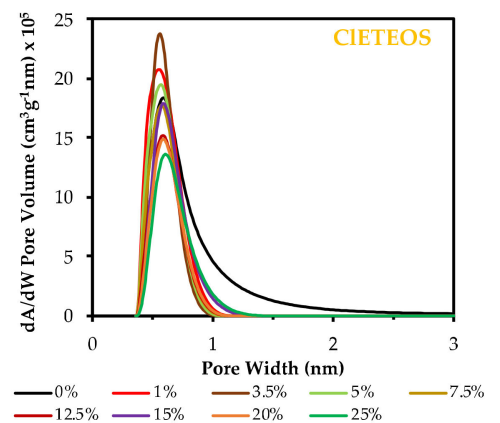

(c)

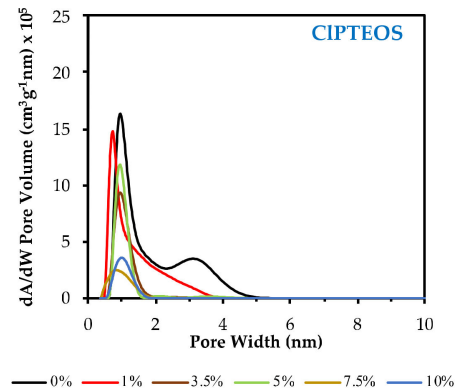

(f)

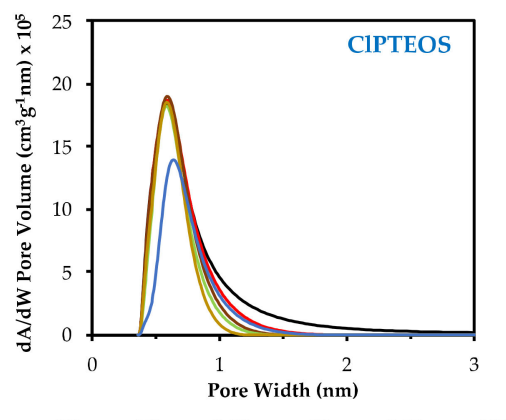

Figure 7. Density-functional theory (DFT) porosity distribution obtained from $\mathrm{N}_{2}$ isotherms of: (a) CIMTEOS:TEOS series, (b) CIETEOS:TEOS series, and (c) CIPTEOS:TEOS series and from $\mathrm{CO}_{2}$ isotherms of: (d) CIMTEOS:TEOS series, (e) ClETEOS:TEOS series, and (f) CIPTEOS:TEOS series.

\subsection{Field-Emission Scanning Electron Microscopy (FE-SEM)}

Figure 8 depicts FE-SEM micrographs of the reference material and a sample of each series synthesized with chloroalkyl precursors (see Figure S3 for micrographs at lower molar percentages). The surface of samples in Figure 8 was studied with energy-dispersive X-ray spectroscopy (EDX) to confirm that the chlorine atoms of the chloroalkyl precursors are homogeneously distributed on their surface (Figure S4).

The reference material (Figure 8a) has a rough surface made up of globular particles that melt, giving it a scaly appearance. The particle diameter ranges from 110 to $150 \mathrm{~nm}$, and the inter-particle spacing correlates with the narrow mesoporosity recorded by the isotherm [57]. The surface of the xerogel synthesized with 1\% CIMTEOS (Figure S3a) is also formed by globular particles, which are smaller and difficult to detect. This morphological change results from both the increase in pore volume and the transition from cone to ink-bottle shaped pores. The surface particles fade with increased molar percentage of CIMTEOS, which gives rise to thin layers that overlap and intersect, yielding a highly microporous and compact material in accordance with its isotherm (Type I(a)).

Micrographs of the CIETEOS series (Figure 8c and Figure S3d-f) show smooth flakelike surfaces consistent with the lack of $\mathrm{N}_{2}$ adsorption of this xerogels. The same pattern is observed in the CIPTEOS series (Figure 8d and Figure S3g-i), although a larger amount of precursor is needed to bring about these changes. 
(a)

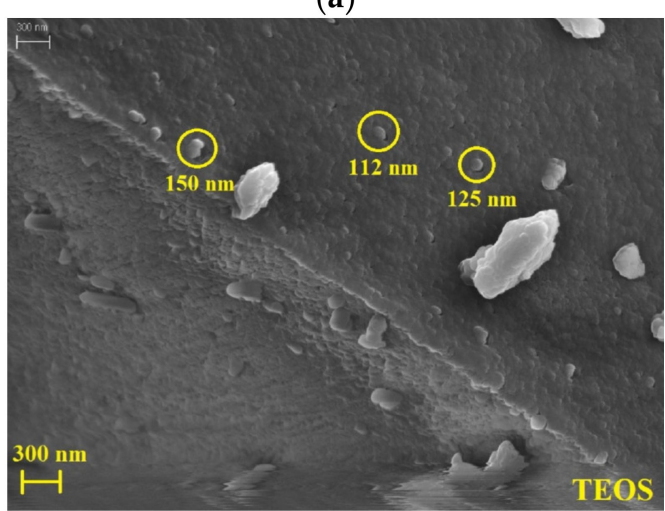

(c)

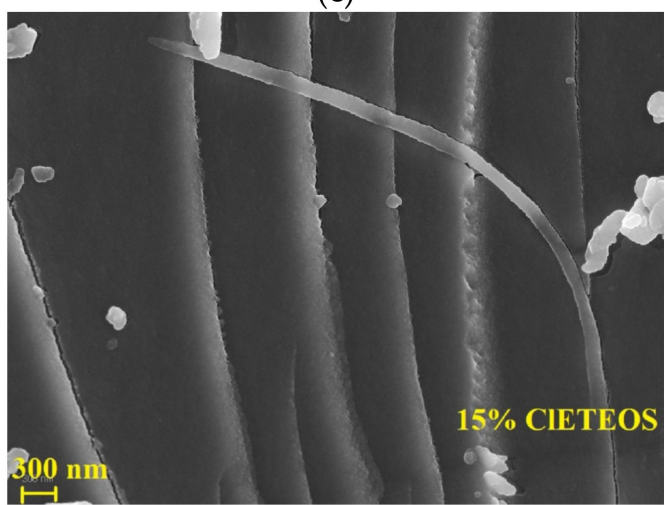

(b)

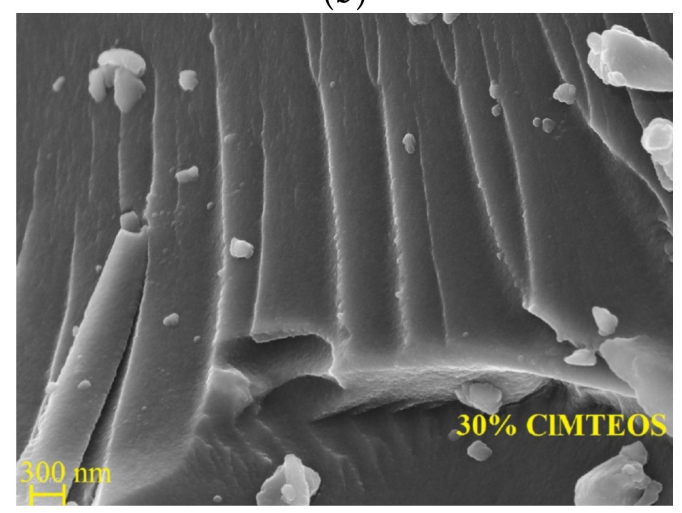

(d)

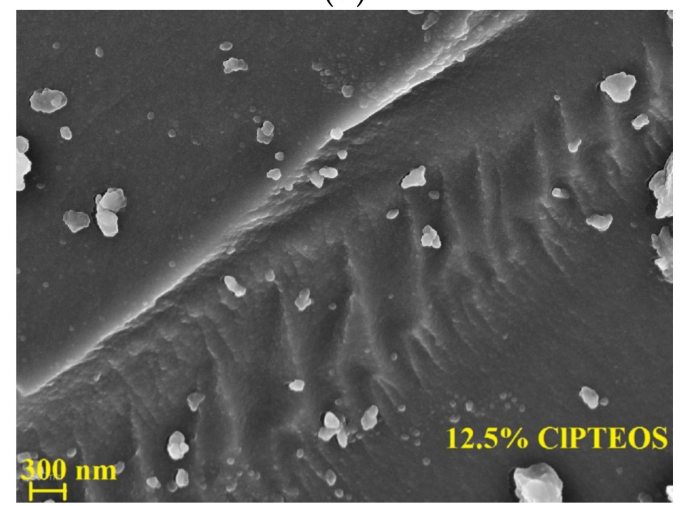

Figure 8. FE-SEM micrographs of: (a) reference xerogel (100\% TEOS), (b) xerogel synthesized with 30\% of ClMTEOS, (c) xerogel synthesized with $15 \%$ ClETEOS, and (d) xerogels synthesized with $12.5 \%$ ClPTEOS.

In all three CIRTEOS series, the particle size decreases with higher percentages of the precursor. This effect is associated with the lower degree of triethoxysilane cross-linking in comparison to TEOS and with the nanostructuration generated to minimize the repulsion between colloids caused by the surface chloroalkyl groups. The decrease in particle size results in the formation of compact but less dense sheets that are responsible for the lower mesoporosity and lesser $\mathrm{N}_{2}$ adsorption of these materials.

\section{Conclusions}

Hybrid CIRTEOS:TEOS xerogels were prepared at $\mathrm{pH}=4.5$ up to molar percentages of 35\% (CIMTEOS) and 25\% (CIETEOS and CIPTEOS). Signals of triethoxysilanes $\left(\mathrm{T}^{\mathrm{n}}\right)$ in ${ }^{29} \mathrm{Si}$ NMR spectra confirm the presence of the chloroalkyl substituents in the silicon matrix, indicating the stability of $\mathrm{Si}-\mathrm{C}$ bonds under the synthesis conditions used. These signals are mainly found for the most condensed species $\left(\mathrm{T}^{3}\right)$ in the CIMTEOS and CIETEOS series, observing a greater proportion of condensed species of TEOS, $\mathrm{Q}^{3}$, and $\mathrm{Q}^{4}$, with a higher percentage of the precursor. This predominance of the most condensed species is consistent with the presence of a signal at a small angle $\left(2 \theta<10^{\circ}\right)$ in the XRD spectra and with the shortening of Si-O-Si bonds compared with their non-chlorinated analogues, indicating the presence of ordered domains constituted by tight and compact structures, such as short ladders and $\mathrm{T}_{8}$ cages. The three series of xerogels show higher skeletal densities in comparison to their analogous non-chlorinated series due to the electronic and steric effects of the chloroalkyl precursor. With regard to the texture of the materials, FE-SEM micrographs show changes in their surface morphology from a granular to a smoother and more compact texture with higher precursor percentages. These modifications also reflect the decrease in $\mathrm{N}_{2}$ and $\mathrm{CO}_{2}$ adsorption capacity recorded by the isotherms with a higher percentage of precursor, allowing materials with different pore sizes to be tailored. XRD spectra show that the chloroalkyl moiety of the precursors more efficiently promotes the 
ordering of the local structure in comparison to the alkyl chain in their non-chlorinated analogues. Strikingly, a very small amount of precursor ( $1 \%$ molar percentage) is required in the CIETEOS series to induce periodic domains formed by well-defined ladders and $\mathrm{T}_{8}$ cagelike structures, producing a significant change in both structural and textural properties with respect to the reference material. The synthesis of these new locally nanostructured hybrid materials with tunable porosities opens up a very promising path for their use in a wide range of applications such as membranes, conductive films, absorbents, catalysis, optoelectronics, and coatings for optical sensors.

Supplementary Materials: The following are available online at https://www.mdpi.com/article/ 10.3390/polym13091415/s1, Table S1: Gelation times of chloroalkyltriethoxysilane (CIRTEOS): tetraethoxysilane (TEOS) materials. Figure S1: FTIR spectra of the xerogels synthesized with $15 \%$ precursor in the ranges: (a) $1600-400 \mathrm{~cm}^{-1}$ and (b) $4000-2750 \mathrm{~cm}^{-1}$; Figure S2: $\mathrm{N}_{2}$ adsorption isotherms at $-196{ }^{\circ} \mathrm{C}$ on a semi-logarithmic scale of the reference material and the hybrids: (a) chloromethyltriethoxysilane (CIMTEOS):TEOS, (b) chloroethyltriethoxysilane (CIETEOS):TEOS, and (c) chloropropyltriethoxysilane (CIPTEOS):TEOS; Figure S3: FE-SEM micrographs of (a) reference material $(b-e)$ CIMTEOS:TEOS materials, (f-i) CIETEOS:TEOS materials, and ( $j-m)$ CIPTEOS:TEOS materials; Figure S4: SEM micrographs of the chloroalkyl materials: (a-c) Distributions of chlorine atoms on the surface of xerogels obtained by applying energy-dispersive X-ray spectroscopy (EDX), $(\mathrm{d}-\mathrm{f})$ Sum of the EDX spectra obtained by analyzing different points of the micrographs $(\mathrm{g}-\mathrm{i})$.

Author Contributions: G.C.-Q.: investigation, writing-original draft. M.E.-V.: methodology, resources, writing—review and editing. M.V.L.-R. Writing—review and editing. J.J.G.: conceptualization, supervision, project administration, funding acquisition, writing — review and editing. All authors have read and agreed to the published version of the manuscript.

Funding: This research was funded by the Ministerio de Economía y Competitividad (Project ref. MAT2016-78155-C2-2-R).

Institutional Review Board Statement: Not applicable.

Informed Consent Statement: Not applicable.

Data Availability Statement: The data presented in this study are available on request from the corresponding author.

Acknowledgments: The authors gratefully acknowledge the financial support received from the Ministerio de Economia y Competitividad from Spain (Project MAT2016-78155-C2-2-R). G.C. is thankful to MINECO and "Ministerio de Ciencia, investigación y Universidades" of Spain government for the "formación de profesorado universitario (FPU)" grant (FPU18/03467). M.E. is thankful to the "Departamento de Industria y Tecnología, Comercio y Trabajo" of Navarre Government for a grant. Authors would also like to acknowledge the use of the "Centro de Instrumentación Científico-Técnica" at the University of Jaén and UCTAI at the Public University of Navarre.

Conflicts of Interest: The authors declare no conflict of interest.

\section{References}

1. Judeinstein, P.; Sanchez, C. Hybrid organic-inorganic materials: A land of multidisciplinarity. J. Mater. Chem. 1996, 6, 511-525. [CrossRef]

2. Pastore, A.; Badocco, D.; Pastore, P. Influence of surfactant chain length, counterion and OrMoSil precursors on reversibility and working interval of $\mathrm{pH}$ colorimetric sensors. Talanta 2020, 212, 120739. [CrossRef] [PubMed]

3. Gillanders, R.N.; Campbell, I.A.; Glackin, J.M.E.; Samuel, I.D.W.; Turnbull, G.A. Ormosil-coated conjugated polymers for the detection of explosives in aqueous environments. Talanta 2018, 179, 426-429. [CrossRef] [PubMed]

4. Li, Z.; Suslick, K.S. Ultrasonic Preparation of Porous Silica-Dye Microspheres: Sensors for Quantification of Urinary Trimethylamine N-Oxide. ACS Appl. Mater. Interfaces 2018, 10, 15820-15828. [CrossRef]

5. Echeverría, J.C.; De Vicente, P.; Estella, J.; Garrido, J.J. A fiber-optic sensor to detect volatile organic compounds based on a porous silica xerogel film. Talanta 2012, 99, 433-440. [CrossRef]

6. Echeverría, J.C.; Calleja, I.; Moriones, P.; Garrido, J.J. Fiber optic sensors based on hybrid phenyl-silica xerogel films to detect n-hexane: Determination of the isosteric enthalpy of adsorption. Beilstein J. Nanotechnol. 2017, 8, 475-484. [CrossRef] 
7. Niu, L.; Zhou, G.; Miao, X.; Yuan, X.; Kumar, R.; Liu, H.; Jiang, Y.; Zou, X.; Zhou, H.; Lü, H. Micro/Nanofiber with Hollow Silica Nanoparticles Thin-Film for Airborne Molecular Contaminants Real-Time Sensing. Hindawi Adv. Condens. Matter Phys. 2018, 2018, 1-6. [CrossRef]

8. Shamir, D.; Elias, I.; Albo, Y.; Meyerstein, D.; Burg, A. ORMOSIL-entrapped copper complex as electrocatalyst for the heterogeneous de-chlorination of alkyl halides. Inorg. Chim. Acta 2020, 500, 119225. [CrossRef]

9. Ponamoreva, O.N.; Afonina, E.L.; Kamanina, O.A.; Lavrova, D.G.; Arlyapov, V.A.; Alferov, V.A.; Boronin, A.M. Yeast Debaryomyces hansenii within ORMOSIL Shells as a Heterogeneous Biocatalyst. Appl. Biochem. Microbiol. 2018, 54, 736-742. [CrossRef]

10. Lin, W.; Zhang, X.; Cai, Q.; Yang, W.; Chen, H. Dehydrogenation-driven assembly of transparent and durable superhydrophobic ORMOSIL coatings on cellulose-based substrates. Cellulose 2020, 27, 7805-7821. [CrossRef]

11. Liu, Z.; Tian, S.; Li, Q.; Wang, J.; Pu, J.; Wang, G.; Zhao, W.; Feng, F.; Qin, J.; Ren, L. Integrated Dual-Functional ORMOSIL Coatings with AgNPs@rGO Nanocomposite for Corrosion Resistance and Antifouling Applications. ACS Sustain. Chem. Eng 2020, 8, 6786-6797. [CrossRef]

12. Scotland, K.M.; Shetranjiwalla, S.; Vreugdenhil, A.J. Curable hybrid materials for corrosion protection of steel: Development and application of UV-cured 3-methacryloxypropyltrimethoxysilane-derived coating. J. Coat. Technol. Res. 2020, 17, 977-989. [CrossRef]

13. Bouvet-Marchand, A.; Graillot, A.; Abel, M.; Koudia, M.; Boutevin, G.; Loubat, C.; Grosso, D. Distribution of fluoroalkylsilanes in hydrophobic hybrid sol-gel coatings obtained by co-condensation. J. Mater. Chem. A. 2018, 6, 24899-24910. [CrossRef]

14. Yue, D.; Feng, Q.; Huang, X.; Zhang, X.; Chen, H. In situ fabrication of a superhydrophobic ORMOSIL coating on wood by an ammonia-HMDS vapor treatment. Coatings 2019, 9, 556. [CrossRef]

15. Malek, S.K.; Nodeh, H.R.; Akbari-Adergani, B. Silica-based magnetic hybrid nanocomposite for the extraction and preconcentration of some organophosphorus pesticides before gas chromatography. J. Sep. Sci. 2018, 41, 2934-2941. [CrossRef] [PubMed]

16. Moriones, P.; Ríos, X.; Echeverría, J.C.; Garrido, J.J.; Pires, J.; Pinto, M. Hybrid organic-inorganic phenyl stationary phases for the gas separation of organic binary mixtures. Colloids Surfaces A Physicochem. Eng. Asp. 2011, 389, 69-75. [CrossRef]

17. Zanut, A.; Palomba, F.; Scota, M.R.; Rebeccani, S.; Marcaccio, M.; Genovese, D.; Rampazzo, E.; valenti, G.; Paolucci, F.; Prodi, L. Dye-Doped Silica Nanoparticles for Enhanced ECL-Based Immunoassay. Angew. Chem. Int. Ed. 2020, 59, 21858-21863. [CrossRef]

18. Meroni, D.; Ardizzone, S.; Cappelletti, G.; Ceotto, M.; Ratti, M.; Annunziata, R.; Benaglia, M.; Raimondi, L. Interplay between Chemistry and Texture in Hydrophobic $\mathrm{TIO}_{2}$ Hybrids. J. Phys. Chem. C 2011, 115, 18649-18658. [CrossRef]

19. Alemán, J.; Chadwick, A.V.; He, J.; Hess, M.; Horie, K.; Jones, R.G.; Kratochvíl, P.; Meisel, I.; Mita, I.; Moad, G.; et al. Definitions of terms relating to the structure and processing of sols, gels, networks, and inorganic-organic hybrid materials (IUPAC recommendations 2007). Pure Appl. Chem. 2007, 79, 1801-1829. [CrossRef]

20. Rios, X.; Moriones, P.; Echeverría, J.C.; Luquín, A.; Laguna, M.; Garrido, J.J. Characterisation of hybrid xerogels synthesised in acid media using methyltriethoxysilane (MTEOS) and tetraethoxysilane (TEOS) as precursors. Adsorption 2011, 17, 583-593. [CrossRef]

21. Rios, X.; Moriones, P.; Echeverría, J.C.; Luquin, A.; Laguna, M.; Garrido, J.J. Ethyl group as matrix modifier and inducer of ordered domains in hybrid xerogels synthesised in acidic media using ethyltriethoxysilane (ETEOS) and tetraethoxysilane (TEOS) as precursors. Mater. Chem. Phys. 2013, 141, 166-174. [CrossRef]

22. Moriones, P. Sintesis y Caracterización de Xerogeles Silíceos Híbridos (RTEOS/TEOS; R = P, Ph). Universidad Pública de Navarra: Pamplona, Spain, 2015. Available online: https:/ / academica-e.unavarra.es/handle/2454/20351 (accessed on 14 November 2020).

23. Chemtob, A.; Ni, L.; Croutxé-Barghorn, C.; Boury, B. Ordered Hybrids from Template-Free Organosilane Self-Assembly. Chem. Eur. J. 2014, 20, 1790-1806. [CrossRef] [PubMed]

24. Chen, Y.; Shi, J. Chemistry of Mesoporous Organosilica in Nanotechnology: Molecularly Organic-Inorganic Hybridization into Frameworks. Adv. Mat. 2016, 28, 3235-3272. [CrossRef] [PubMed]

25. Clara Gonçalves, M. Physisorption data for methyl-hybrid silica gels. J. Sol-Gel Sci. Technol. 2015, 75, 508-518. [CrossRef]

26. Ramezani, M.; Vaezi, M.R.; Kazemzadeh, A. The influence of the hydrophobic agent, catalyst, solvent and water content on the wetting properties of the silica films prepared by one-step sol-gel method. Appl. Surf. Sci. 2015, 326, 99-106. [CrossRef]

27. Estella, J.; Echeverría, J.C.; Laguna, M.; Garrido, J.J. Silica xerogels of tailored porosity as support matrix for optical chemical sensors. Simultaneous effect of $\mathrm{pH}$, ethanol: TEOS and water: TEOS molar ratios, and synthesis temperature on gelation time, and textural and structural properties. J. Non. Cryst. Solids. 2007, 353, 286-294. [CrossRef]

28. Estella, J.; Echeverría, J.C.; Laguna, M.; Garrido, J.J. Effects of aging and drying conditions on the structural and textural properties of silica gels. Microporous Mesoporous Mater. 2007, 102, 274-282. [CrossRef]

29. Flores-López, S.L.; Villanueva, S.F.; Montes-Durán, M.A.; Cruz, G.; Garrido, J.J.; Arenillas, A. Advantages of microwave-assisted Synthesis of Silica Gels. Colloids Surf. A 2020, 604, 125248. [CrossRef]

30. Yoshitake, H.; Kodate, T.; Takagi, T.; Kawamura, I.; naito, A. Polysilsesquioxanes with mixed self-assembled organic tethers Alkylchains and alkanoate-aminopropyl pairs. React. Funct. Polym. 2016, 99, 9-16. [CrossRef]

31. Zacca, M.J.; Laurencin, D.; Richeter, S.; Clément, S.; Mehdi, A. New Layered Polythiophene-Silica Composite Through the Self-Assembly and Polymerization of Thiophene-Based Silylated Molecular Precursors. Molecules 2018, 23, 2510. [CrossRef] [PubMed] 
32. Ospino, I.; Luquin, A.; Jiménez-Ruiz, M.; Pérez-Landazábal, J.I.; Recarte, V.; Echeverría, J.C.; Laguna, M.; Urtasun, A.A.; Garrido, J.J. Computational Modeling and Inelastic Neutron Scattering Contributions to the Study of Methyl-silica Xerogels: A Combined Theoretical and Experimental Analysis. J. Phys. Chem. C 2017, 121, 22836-22845. [CrossRef]

33. Tran, J.A.; Shea, K.J.; Loy, D.A. Methylene-bridged polysilsesquioxaes: Substitution of a methylene spacer within a silicate matrix. J. Mater. Sci. 2014, 49, 5006-5016. [CrossRef]

34. Siriwong, C.; Sae-Oui, P.; Sirisinha, C. Comparison of coupling effectiveness among amino-, chloro-, and mercapto silanes in chloroprene rubber. Polym. Test. 2014, 38, 64-72. [CrossRef]

35. Chen, G.; Zhou, Y.; Wang, X.; Li, J.; Xue, S.; Liu, Y.; Wang, Q.; Wang, J. Construction of porous cationic frameworks by crosslinking polyhedral oligomeric silsesquioxane units with N-heterocyclic linkers. Sci. Rep. 2015, 5, 1-14. [CrossRef]

36. Innocenzi, P. The Sol-Gel Transition, 2nd edSpringer: Sassari, Italy, 2019. [CrossRef]

37. Musgo, J.; Echeverría, J.C.; Estella, J.; Laguna, M.; Garrido, J.J. Ammonia-catalyzed silica xerogels: Simultaneous effects of pH, synthesis temperature, and ethanol: TEOS and water: TEOS molar ratios on textural and structural properties. Microporous Mesoporous Mater. 2009, 118, 280-287. [CrossRef]

38. Brinker, C.J.; Scherer, G.W. The Physics and Chemistry of Sol Gel Processing, 1st ed.; Academic Press Inc.: London, UK, 1990. [CrossRef]

39. Kickelbick, G. Hybrid Materials Synthesis Characterization and Applications, 1st ed.Wiley-VCH Verlag GmbH \& Co. KGaA: Wien, Austria, 2007. [CrossRef]

40. Hall, C.J.; Ponnusamy, T.; Murphy, P.J.; Lindberg, M.; Antzutkin, O.N.; Griesser, H.J. A Solid-State Nuclear Magnetic Resonance Study of Post-Plasma Reactions in Organosilicone Microwave Plasma-Enhanced Chemical Vapor Deposition (PECVD) Coatings. ACS appl. Mater. Interfaces 2014, 6, 8353-8362. [CrossRef]

41. Sakka, S. Handbook of Sol-Gel Science and Technology_Processing, Characterization and Application Volume II: Charact. Sol-Gel Mater. Prod., 1st ed.; Kluwer Academic Publishers: Norwell, MA, USA, 2005. [CrossRef]

42. Rouquerol, F.; Rouquerol, J.; Sing, K.S.W.; Llewellyn, P.; Maurin, G. Adsorption by Powders and Porous Solids Principles, Methodology and Applications, 2nd ed.; Academic Press: San Diego, CA, USA, 1999. [CrossRef]

43. Garrido, J.; Linares-solano, A.; Martìn-Martìnez, J.M.; Molina-Sabio, M.; Rodrìguez-Reinoso, F.; Torregrosa, R. Use of N2 vs: CO2 in the Characterization of Activated Carbons. Langmuir 1987, 3, 76-81. [CrossRef]

44. García-Martínez, J.; Cazorla-Amorós, D.; Linares-Solano, A. Further evidences of the usefulness of CO2 adsorption to characterise microporous solids. Stud. Surf. Sci. Catal. 2000, 128, 485-494. [CrossRef]

45. Torres-Luna, J.A.; Garriazo, J.G. Porous aluminosilicic solids obtained by thermal-acid modification of acommercial kaolinite-type natural clay. Solid State Sciences. 2019, 88, 29-35. [CrossRef]

46. Sun, Y.; Zhang, Z. Structural Roles of Boron and Silicon in the CaOSiO2-B2O3 Glasses Using FTIR, Raman, and NMR Spectroscopy. Metall. and Mater. Trans. B. 2015, 46, 1549-1554. [CrossRef]

47. El Felss, N.; Gharzouni, A.; Colas, M.; Cornette, J.; Sobrados, I.; Rossignol, S. Structural study of the effect of mineral additives on the transparency, stability, and aging of silicate gels. J. Sol-Gel Sci. Technol. 2020, 96, 265-275. [CrossRef]

48. Park, E.S.; Ro, H.W.; Nguyen, C.V.; Jaffe, R.L.; Yoon, D.Y. Infrared spectroscopy study of microstructures of poly(silsesquioxane)s. Chem. Mater. 2008, 20, 1548-1554. [CrossRef]

49. Uhlig, F.; Marsman, H.C. 29Si NMR—Some Practical Aspects. Gelest Inc.: Morrisville, PA, USA, 2008; pp. 208-222. Available online: http:/ / www.gelest.com (accessed on 16 January 2021).

50. Vasil'ev, S.G.; Volkov, V.I.; Tatarinova, E.A.; Muzafarov, A.M. A Solid-State NMR Investigation of MQ Silicone Copolymers. Appl. Magn. Reson. 2013, 44, 1015-1025. [CrossRef]

51. Ivanovski, V.; Mayerhöfer, T.G.; Kriltz, A.; Popp, J. IR-ATR investigation of surface anisotropy in silicate glasses. Spectrochim. Acta-Part A Mol. Biomol. Spectrosc. 2017, 173, 608. [CrossRef] [PubMed]

52. Park, S.; Kim, J.Y.; Choi, W.; Lee, M.J.; Heo, J.; Choi, D.; Jung, S.; Kwon, J.; Choi, S.H.; Hong, J. Ladder-like polysilsesquioxanes with antibacterial chains and durable siloxane networks. Chem. Eng. J. 2020, 393, 124686. [CrossRef]

53. Li, Q.; Guo, L.; Qiu, T.; Ye, J.; He, L.; Li, C.; Tuo, X. Polyurethane/polyphenylsilsequiloxane nanocomposite: From waterborne dispersions to coating films. Prog. Org. Coatings 2018, 122, 19-29. [CrossRef]

54. Thommes, M.; Kaneko, K.; Neimark, A.V.; Olivier, J.P.; Rodriguez-Reinoso, F.; Rouquerol, J.; Sing, K.S.W. Physisorption of gases, with special reference to the evaluation of surface area and pore size distribution (IUPAC Technical Report). Pure Appl. Chem. 2015, 87, 1051-1069. [CrossRef]

55. Dudás, Z.; Len, A.; Ianăși, C.; Paladini, G. Structural modifications caused by the increasing MTES amount in hybrid MTES/TEOSbased silica xerogels. Mater. Charact. 2020, 167, 33-36. [CrossRef]

56. Echeverría, J.C.; Estella, J.; Barbería, V.; Musgo, J.; Garrido, J.J. Synthesis and characterization of ultramicroporous silica xerogels. J. Non. Cryst. Solids. 2010, 356, 378-382. [CrossRef]

57. Liu, Q.; Zhang, J.; Sun, W.; Xie, Q.R.; Xia, W.; Gu, H. Delivering hydrophilic and hydrophobic chemotherapeutics simultaneously by magnetic mesoporous silica nanoparticles to inhibit cancer cells. Int. J. Nanomed. 2012, 7, 999-1013. [CrossRef] 